Fecha de recepción: mayo 2020 Fecha de aceptación: junio 2020 Versión final: julio 2020

\section{Diseño, tipografía y comunicación \\ visual. Ahora todo vale}

Gerardo Gómez Romero ${ }^{*}$

Resumen: En el marco del Diseño Gráfico las expresiones documentadas de los diferentes períodos, son parte de la historia del hombre, y aunque los primeros vestigios gráficos y de escritura no siguieron un patrón normativo, las creaciones se dieron en un proceso lento -con adversidades-, pero finalmente efectivo para la evolución. El diseño gráfico y la tipografía no quedan al margen de las trasformaciones; los fundamentos del diseño, las normas tipográficas y la metodología fueron factores que sistematizaron los procesos. Pareciera una lucha entre creadores conservadores, ortodoxos del diseño versus liberales posmodernos que desafían a la academia y toda manifestación de diseño regulada por las normas. Este escrito aborda al diseño gráfico y la tipografía con perspectiva de comunicación visual, el cruce con la ética en el desempeño profesional, a partir de las implicaciones pragmáticas, semánticas y sintácticas de algunos casos de diseño que se presentan, el análisis y confrontación con lo que pudiera ser correcto o incorrecto en la significación de un diseño. Para tal cruce, el punto de partida se sustenta en los fundamentos del diseño y las normas tipográficas, estructuras planteadas como sistemas reguladoras de orden, en confrontación con la puesta en escena de soportes gráficos no convencionales, donde se vulneran los principios académicos del diseño y se quebrantan las normas tipográficas. Para el final del documento se reflexionará sobre las manifestaciones actuales del diseño gráfico y la postura ética del diseñador, tanto conservadores como de liberales; si en la actualidad realmente 'todo vale', aspectos que se podrán analizar y de las que se podrán sacar conclusiones a partir de lo expuesto.

Palabras clave: ética - razón - normas - diseño - tipografía.

[Resúmenes en inglés y portugués en las páginas 99-100]

(*) Profesor de Carrera de tiempo completo, Titular "A" Definitivo, con adscripción al Posgrado de la Facultad de Artes y Diseño (FAD) de la Universidad Nacional Autónoma México (UNAM). Su cátedra y proyectos de investigación están vinculados con los temas de tipografía, diseño y publicaciones electrónicas. Obtuvo el grado de Doctor en Artes y Diseño por la misma Universidad. En el medio profesional se desempeña como diseñador gráfico eventual, logrando una carpeta de trabajos publicados en diversos soportes, durante los últimos 30 años. dgintegral@yahoo.com.mx 


\section{Antecedentes de una inminente transformación}

En el siglo XVIII, el crecimiento de la población -principalmente en Europa-, se incrementó en un ritmo diferente en comparación de los siglos anteriores. Como consecuencia, los problemas se agudizaron cada vez más; enfermedades, pandemias, desnutrición y una cadena de carencias provocó un alto índice de mortandad, en un entorno donde prevaleció la vida basada en la agricultura, ganadería y la producción artesanal. Los sistemas de producción se quedaron cortos en el abasto de cualquier tipo de insumo, además los lentos y limitados sistemas de comunicación dificultaron el intercambio comercial, social y cultural entre los pueblos.

Una serie de cambios propició una inminente transformación en el proceso de modernización de las naciones; los primeros esfuerzos se dieron en Inglaterra durante el último tercio del siglo XVIII y de allí se expandió a toda Europa, Japón y los Estados Unidos. Los resultados se potenciaron con la Revolución Industrial (1760-1840), cuando el sector agrario, comercial, de comunicaciones y principalmente el industrial, se transformaron sus procesos artesanales en sistemas de producción en masa con la implementación de innovadas técnicas asociadas a la proliferación de maquinaria para la fabricación de un sinnúmero de herramientas y objetos en beneficio de las sociedades. La industria de las artes gráficas no quedó relegada; en la segunda etapa de la Revolución Industrial -principios del siglo XIX- la imprenta experimentó los primeros logros utilizando placas de metal, desplazando a la litografía, así como también los tipos móviles de Gutenberg. Después de diversas colaboraciones en todo el mundo, la máquina de offset fue una auténtica revolución, que terminó por capitalizar el estadunidense Washington Rubel hacia principio del siglo XX. Con este avance, la producción de publicaciones -de todo tipo- aumentó de forma exponencial, beneficiando la difusión de la cultura a nivel mundial.

Paralelo al desarrollo tecnológico, se gestó la idea de un 'mundo mejor', propio del pensamiento de la modernidad; una sociedad con más comodidades, excluyente y antidemocrática en el que la ética tuvo serios cuestionamientos. En las primeras décadas del siglo pasado, el diseño en sus diferentes disciplinas desempeñó un papel protagónico. Los acontecimientos mundiales del nuevo siglo pusieron en predicamento a la ética y la moral empleada. $\mathrm{Al}$ respecto, Zygmunt Bauman (2005) señala que "El 'movimiento moderno' pulverizó cualquier sustento sobre el que podría imaginarse un fundamento moral -de hecho, minó la moralidad-” (p. 249). En cuestión, Dora Elvira García G. (2012) establece que:

Usualmente no hay una distinción clara entre los términos ética y moral, ya que ni en su uso ni en su etimología existe una distinción [...] es necesario señalar dos niveles de reflexión y lenguaje: por un lado, el nivel de la vida cotidiana en donde se vive con ciertos referentes morales y por otro, el de la filosofía moral que reflexiona sobre la moral vivida en la cotidianidad [...] se pueden dividir las acciones de los hombres en tres grupos, a) Morales: acciones que son libres y que emanan de algunos valores, que son voluntarias, es decir que conllevan decisiones libres. b) Inmorales: aquellas que al ser libres, se oponen a lo que debería hacerse en tanto va en contra de la perfección y la construcción 
humana. En este sentido, por eso se dice que va en contra de lo valioso, de los valores humanos. C) Amorales: aquellas acciones que no tiene que ver con la moralidad, que no implican a la libertad como sí lo hacen las dos anteriores. (p. 12-14).

\section{Tecnología para el desarrollo del diseño}

A partir de los avances tecnológicos, la industria editorial y publicitaria tuvieron que adecuar los procesos de edición y producción a partir de los formatos de la nueva tecnología. Para inicios del siglo XX, países como Alemania, Inglaterra, Rusia y los Estados Unidos se convirtieron en productores y exportadores de tecnología y maquinaria. Un claro ejemplo de desarrollo tecnológico para el diseño y homologación en los procesos es el sistema Deustche Industrie Normen, conocido como sistema DIN. El mismo, se implementó en Europa para estandarizar los formatos de papel (Elam, 2014). El formato geométrico del sistema DIN se estableció a partir del rectángulo raíz de 2, la subdivisión infinita de rectángulos corresponde a la proporción estética de la sección áurea. Con la facultad de dividirse por la mitad, en cuartos y octavos de hoja y no presentar desperdicio de papel. En el siguiente diagrama se observa la construcción de rectángulos áureos.

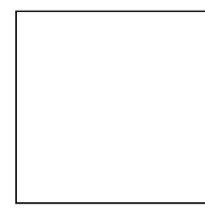

Paso no. 1

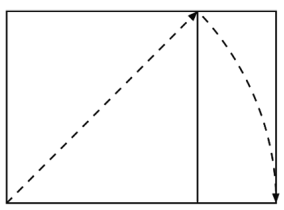

Paso no. 2

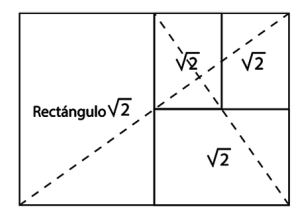

Paso no. 3

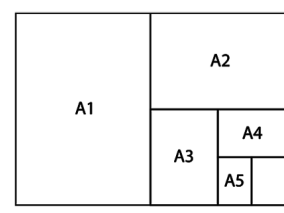

Paso no. 4

Figura 1. Construcción de rectángulo armónico raíz de 2. Fuente: Kimberly, 2014, p. 34

En la mayoría de los países europeos se estandarizó el uso de los diferentes formatos comerciales a partir de esta geometría, utilizados tanto para la publicidad impresa, como para documentos legales y académicos. Este sistema significó la ingeniería de regulación internacional en los procesos de producción, tanto para la industria de las artes gráficas como para el equipo de escritorio; una muestra de planeación y orden, producto de la razón en beneficio de las múltiples publicaciones.

Para efectos de reflexión habrá que comprender el contexto de la primera mitad del siglo pasado, de momentos contrastantes que desafiaron la estabilidad mundial; por un lado las sociedades más avanzadas vivieron los ideales de la modernidad, a la par de significativos avances tecnológicos como el teléfono, el automóvil, la luz eléctrica o el avión, por 
mencionar solo algunos. Por otro lado, dos guerras mundiales, que mostraron el horror de la humanidad. Finalmente, el progreso tecnológico propició cambios en las estructuras sociales y en la economía mundial. La transformación dio muestras en campos del diseño totalmente diferentes: textil, automotriz, gráfico, arquitectónico, industrial, etcétera. La retrospectiva ha etiquetado este lapso como 'el siglo de las maravillas', sorprendiendo cada década con muestras trascendentales de desarrollo más que en cualquier otro siglo del pasado. Con relación al tema de la modernidad, Habermas (1981) establece que "el término 'moderno' expresa una y otra vez la conciencia de una época que se pone en relación con el pasado de la antigüedad para verse así misma como el resultado de una transición de lo viejo a lo nuevo" (p. 88).

Uno de los factores que sienta las bases del diseño, no como un producto artesanal, sino como un sistema de producción en serie, se consolida en 1919. Walter Gropius fundó y dirigió la Escuela de la Bauhaus (1919-1933) en Weimar, República Alemana, como respuesta a una prolífica industrialización. En catorce años de vida, la entidad académica tuvo transformaciones ideológicas y políticas que cuestionaron fuertemente el trabajo de diseño frente a las necesidades sociales, por lo que se modificó y adecuó el discurso de cátedra con la realidad de las masas. En este sentido Droste (1991) sostiene: "Los conceptos de reforma pedagógica de la Bauhaus que especialmente había desarrollado Itten, Josef Albers y László Moholy-Nagy, fueron internacionalmente adoptados en los programas educativos en las Escuelas Superiores de Arte y Diseño, donde continuaron evolucionando. (p. 6)".

Los elementos que se gestaron para la propuesta de estilo de la Bauhaus fueron en torno a la forma y al color. Theo van Doesburg junto con Piet Mondrian, encabezaron el grupo de artistas de De Stijl e impulsaron la utilización de los tres colores básicos, complementados con negro, blanco y gris, en la búsqueda por encontrar la expresión y 'soluciones colectivas' (Droste, 1991). Hasta 1922, la Bauhaus no había encontrado los principios en el que fundamentar su filosofía. Fue entonces cuando Gropius orienta el trabajo hacia una nueva tendencia:

... buscaba en sus conferencias un 'denominador común' en la arquitectura, en los talleres se tomaban como punto de partida formas y colores básicos [...] La Bauhaus tiene que 'crear formas típicas, ...que simbolicen el mundo', proclamaba Gropius en 1922. Poco después se dedicaba incansable a la propagación de un nuevo lema: 'Arte y técnica una nueva unidad'. Con ello se alzaba el trabajo de la Bauhaus bajo una divisa completamente nueva, ya que en 1919 se trataba de 'Arte y artesanía - una nueva unidad'. (Droste, 1991, p. 58)

Basándose en los grabados de De Stijl y el constructivismo ruso, la Bauhaus anunció la reivindicación de la modernidad; lo que fue significativo para el contenido de los postulados. Moholy-Nagy que conocía la vanguardia constructivista fue quien implementó dichos postulados académicos en la Bauhaus (Droste, 1991). Los esfuerzos por impulsar el trabajo tipográfico, no solo en el diseño y fundición de 'tipos', también en la parte compositiva, rindió frutos que se materializaron en el taller de impresión y publicidad de la entidad académica. Bayer que estuvo a cargo de éste taller dirigió los trabajos de sus alumnos con las exigen- 
cias de la ciencia, además de profundizar en su cátedra la psicología publicitaria. El sistema educativo teórico y práctico se implementó en los diferentes talleres, algo que no existía hasta entonces; de tal forma que se empezó a desarrollar los medios estratégicos para las nuevas profesiones (Droste, 1991).La praxis personalizada que Bayer imprimió en las aulas y talleres, sentó un precedente importante para el surgimiento de la profesión del diseño gráfico. "Diseño y realización dependieron de una sola persona, lo que permitió estructurar los requisitos para una nueva profesión: el diseño gráfico." (Brüning, 1988, p. 154). No existe fecha exacta ni evento particular que identifique la instauración del diseño gráfico -como se conoce actualmente- pero sin duda, fue un proceso de muchos siglos que se consolido en el siglo XX, con la influencia de los movimientos artísticos de la época como el dadaísmo, suprematismo, constructivismo, De Stijl, entre otros. La visión académica de la Bauhaus transformó los oficios en profesiones bien delimitadas, tanto para las artes visuales como para las diferentes disciplinas del diseño. Una definición oficial de 'diseño gráfico' no ha tenido consenso. Luz del Carmen Vilchis (2010) define al diseño gráfico como la disciplina proyectual orientada hacia la solución de problemas de comunicación visual que el hombre se plantea en su proceso de adaptación al medio, según sus necesidades.

\section{Modernidad y posmodernidad en el Diseño y la tipografía}

El desarrollo del diseño gráfico en el periodo de la modernidad de principios del siglo pasado estuvo vinculado, por un lado, a la innovación tecnológica y por otro, con la expansión de la industria publicitaria donde se profesó un nuevo estilo de vida y en el que cada vez más gente consumía diseño. Al respecto Fraser (1991) señala que las estrategias para satisfacer, mantener y expandir este nuevo mercado de masas, subsumieron la cuestión del diseño mediante su creciente importancia en la publicidad, el marketing y los puntos de venta. De tal forma, la comunicación visual adquiere una presencia importante en la cotidianidad de las personas, y en consecuencia, con los procesos de comercialización. Fue un periodo incesante de transformaciones que moldearon la cultura de las sociedades.

La modernidad era un concepto ilimitado, hasta el punto de que la gente podía imaginar el futuro y proyectar esa visión para influir en el presente. A menudo se experimentaba como una aspiración, una promesa de 'valor añadido' para la vida de las personas, que iba más allá de la 'necesidad' para entrar en el ámbito del 'deseo'. [...] De forma inevitable, los diseñadores a quienes se pagaba por ser imaginativos y visualmente innovadores, formaron una parte esencial de este proceso consistente en anticipar distintos modelos de modernidad que, a su vez, permanecían siempre justo fuera del alcance, gracias a la renovación constante. (Sparke, 2010, p. 34)

En el periodo de guerras mundiales se aplicaron ciertas normas tipográficas sin una línea unificadora, la falta de 'rigurosidad' determinó que el tipógrafo o diseñador aplicara los 
sistemas establecidos dependiendo de las circunstancias de cada trabajo. Para tiempos de posguerra, la preocupación por la unidad en el trabajo profesional se incremento sustancialmente. Uno de los precursores en deshacerse de las normas convencionales de la tipografía tradicional y en establecer nuevas leyes de composición, en consonancia con la era moderna fue el diseñador Emil Ruder; en los inicios de la década de 1980 publicó el 'Manual de diseño tipográfico', en el que puso de manifiesto leyes rigurosas de la tipografía. Estableció conceptos y estructuras globales para el uso de la tipografía y la práctica del diseño gráfico (Ruder, 1982).

Sin embargo, la implementación de sistemas con base en las normas del diseño fue un proceso lento pero firme. Conceptos como legibilidad, claridad, orden, estructura y sistematización se enfatizaron en los postulados. En cuanto a la escritura y la composición tipográfica, la posición de objetividad fue contundente. "La tipografía está sometida a una finalidad precisa: comunicar e informar por medio de la letra impresa. Ningún argumento, ni consideración puede librarla de este deber. La obra impresa que no puede leerse se convierte en un producto sin sentido" (Ruder, 1982, p.8). Cabe señalar que este pensamiento en la década de 1980 fue producto de los ideales que se formularon en el periodo de la modernidad, en el que la 'razón' fue la base de cualquier discurso, así que no existieron subjetividades que pudieran fundamentar trabajos motivados por el sentimiento de la expresión visual, ni las interpretaciones metafóricas.

Después de la segunda guerra mundial, el periodo posmoderno cuestionó severamente lo sucedido en la modernidad, lo que generó dos posiciones de pensamiento confrontados; por un lado, los conservadores, ortodoxos del diseño que apostaron por el orden, la estructura y una legibilidad clara, por otro, los liberales posmodernos que desafiaron toda normatividad y postulados académicos. El debate se centró en la función y en la forma; la funcionalidad de un objeto diseñado convencionalmente está por encima de su apariencia, -si el diseño realizado no cumple con la función, aun cuando éste sea bello, es inútilno obstante, en la actualidad algunas tendencias del diseño postulan a la estética como prioritaria en razón de existir, quedando relegada a un segundo plano la funcionalidad. Los factores que determinan si la forma sigue a la función, o viceversa, son diversas, no se puede determinar un consenso absoluto que establezca que es lo correcto o lo incorrecto. El punto de reflexión sobre lo 'correcto', es cuando el ser humano tiene la capacidad de distinguir entre el bien y el mal. Al respecto, Ana Ma. Narro (2009) define al 'bien' como "el fin de nuestros actos que podemos querer por sí mismos" (p. 3). El trabajo del diseñador está envuelto de constantes decisiones en todo el proceso de creación, por lo que impera la ciencia o conocimiento de este bien, y la relación con la experiencia humana para llegado el momento decidir que es lo que conviene. (Narro, 2009).

Durante el periodo posmoderno, los pensadores de las diferentes disciplinas del diseño cuestionaron de manera enfática las limitaciones para el desarrollo y apoyaron los sistemas alternos de experimentación. Paul Feyerabend (2002) que concluye en un artículo científico "El único principio que no dificulta el progreso es el 'todo vale' (p.23) en él considera al error como parte esencial del progreso. La crisis que se desarrolló en las décadas posteriores a la posguerra incluyó: pobreza, exclusión, injusticia, entre otras, propició en algunas sociedades una actitud despreocupada y desenfocada del mundo, así lo establece 
Dora Elvira García G. (2012) que señala a este fenómeno como 'nihilismo', una actitud para la que no hay nada por lo que valga la pena luchar, ni valores que puedan servir de guías valiosas para la vida, sino que 'todo es posible’. (García G., 2012, p. 16). A pesar de que el periodo posmoderno ya concluyó (11 Sep. 2001) para muchos artistas y diseñadores este pensamiento sobre lo permisible sigue vigente.

A continuación se muestran dos carteles realizados por diseñadores gráficos, que muestran con claridad posturas antagónicas en el diseño y la tipografía. El primero* es de Wim Crouwel realizado en 1968, con una convocatoria en el museo de Ámsterdam. El formato del cartel está construido a partir de un rectángulo raíz de 2 , en él se muestra una retícula de módulos cuadrados los cuales sirven como soporte para el diseño tipográfico. El soporte gráfico evidencia orden, estructura geométrica, contraste total entre el negro y el blanco del papel lo que sugiere limpieza y claridad, además de un estilo racional -literalmente cuadrado-. El segundo** es de Stefan Sagmeister realizado en 1991, para una de sus conferencias en el American Institute of Graphic Arts, el soporte físico que utilizó para la realización del cartel fue su propio cuerpo, el cual ayudado por uno de sus colaboradores es rasgado con una cuchilla y con el que se inscriben los datos informativos de la conferencia, posteriormente es fotografiado e impreso en el formato de cartel. La obra de Sagmeister es un claro ejemplo de diseño posmoderno; para un sector del público fue un atrevimiento extremo mostrar el cuerpo desnudo, además de pronunciar la inconformidad por la ausencia una tipografía sistemática, la falta de estructura compositiva, esquivando cualquier principio del diseño. Bauman (2005) señala que "para una mente moderna, estos sentimientos posmodernos representan un peligro mortal para la convivencia humana” (p. 42).
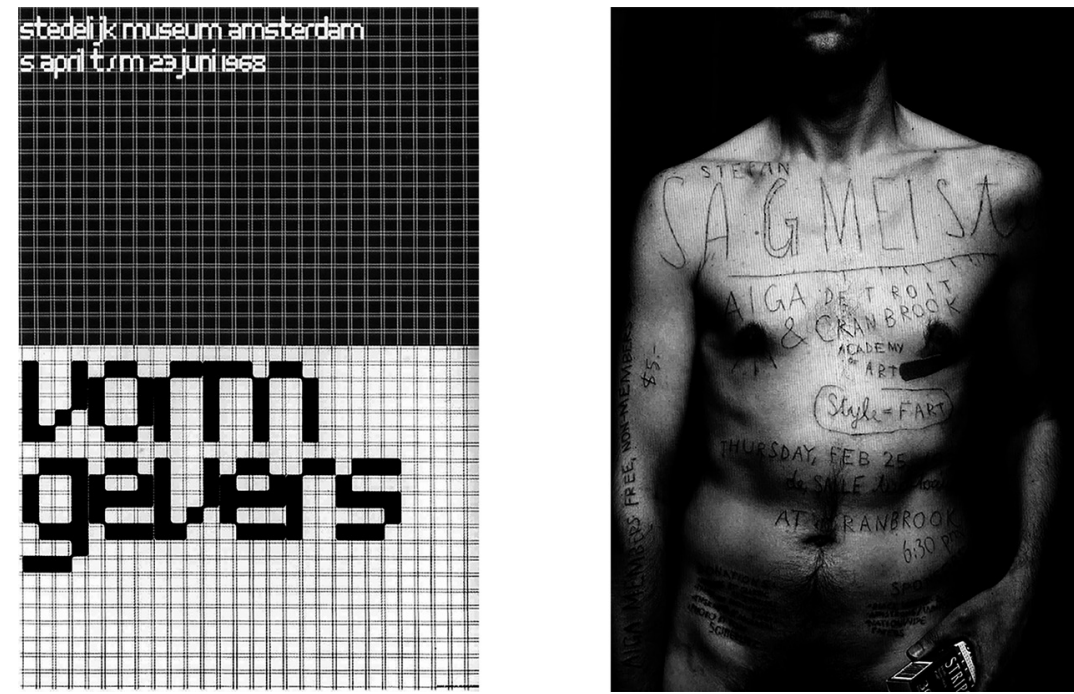

Figura 2. Diseño de carteles de los años 1968 y 1991.

Fuentes: ${ }^{\star}$ Kimberly, 2014, p. $118-{ }^{*}$ Heller - Ilic, 2004, p. 73 
A pesar de la diferencia de épocas en las que fueron realizados estos dos carteles, las propuestas asombraron y fueron significativas para la comunidad artística, influyendo en las tendencias del diseño a nivel mundial, dejando abierto el debate de lo permisible, la libre aceptación o rechazo. Consecuente con estos dos estilos y formas del pensamiento, hubo profesionales del diseño que optaron por el camino académico normativo como lo éticamente correcto, mientras que otros en contraposición, fueron motivados por el estilo intuitivo, libre de estructuras y ataduras a cualquier tipo de norma y con tendencia a la expresión visual.

[...] la mente moderna se siente horrorizada por la perspectiva de la 'desregulación' de la conducta humana, de vivir sin un código ético estricto y abarcador, de apostarle a la intuición moral del ser humano y a su capacidad de negociar el arte y los usos de la convivencia, más que buscar apoyo de reglas legales y despersonalizadas sustentadas en poderes coercitivos. (Bauman, 2005, p. 42).

Tanto en el arte como en diseño, arquitectura y tipografía, el análisis compositivo se fundamenta en las proporciones visuales de una propuesta artística. El factor de composición se somete a la relación de elementos que conforman el todo. Kimberly Elam (2011) acota que "la proporción de una obra es esencial en su composición, establece una serie de relaciones visuales no solo entre la anchura y altura de la pieza, sino también entre las partes y el todo" (p. 46). El análisis geométrico clarifica la construcción de un diseño, expone un diagrama de sostenimiento formal, y en tal caso, si se realiza una inspección rigurosa al armado de la obra, ésta podrá sustentarse con base en la razón.

El análisis geométrico permite identificar los sistemas de proporción y las líneas reguladoras que hacen que una obra de arte, un edificio, un objeto o un trabajo de diseño gráfico muestren una composición coherente. Si bien este análisis no analiza el concepto, la cultura o el medio en que se ha producido la pieza en cuestión, si revela sus principios compositivos y, a menudo confirma -empleando medios cuantificables de proporción y alineación-. El valor del análisis geométrico estriba en revelar las ideas y principios de diseño empleados por artistas, arquitectos y diseñadores en sus obras. (Kimberly Elam, 2011, p. 45).

Así como en el diseño, en la vida las estructuras son parte fundamental del ser humano; en una analogía válida, es el esqueleto que soporta la forma en que se piensa, actúa, habla, es el contenedor en el que está puesta la formación moral. "Los conocimientos de sabiduría serán valiosos en nosotros solo cuando existan las estructuras, es decir, el andamiaje que se construye desde lo más hondo, en lo que somos como personas". (García G., 2012, p.10). Un claro ejemplo de construcción geométrica es el símbolo de la Central de Abastos de la Ciudad de México, realizado por el diseñador Lance Wyman. En el se pueden observar las indicaciones geométricas de segmentos, radios, circunferencias, ángulos y un dibujo de trazos con precisión. El diagrama sustenta principios de diseño, un plan sistemático a partir de una idea racional. A la derecha el resultado final del proyecto. 

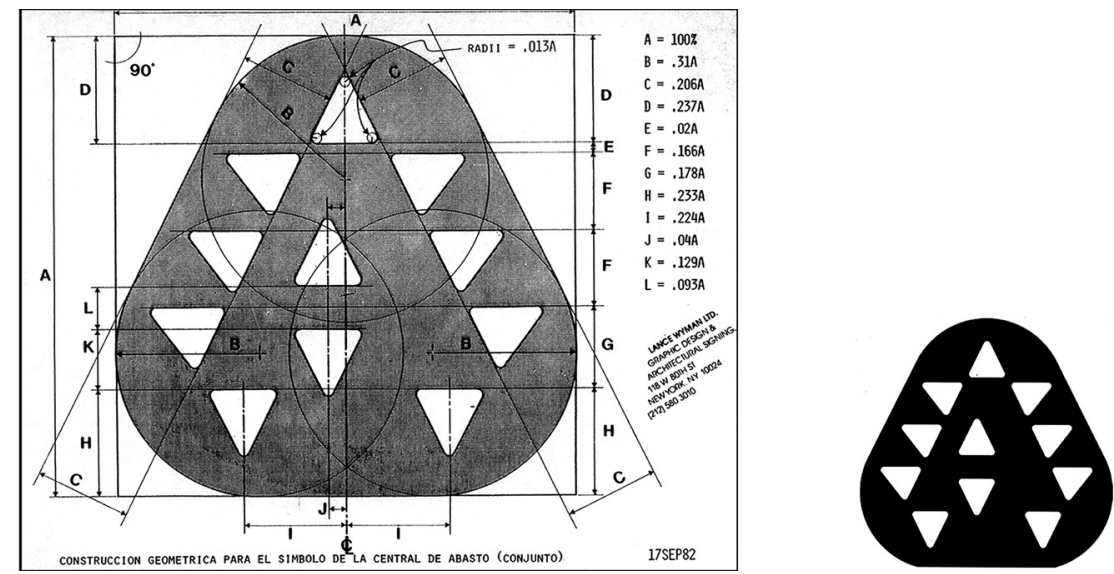

Figura 3. Proyección geométrica de un símbolo. Fuente: Wyman, 2014, p. 202-203

\section{Conocimiento de las normas y su rompimiento}

Terminada la Segunda Guerra Mundial (1939-1945), el diseño gráfico de la década de 1950, tuvo un desarrollo importante, buscó un tipo de reconstrucción que reivindicara el trabajo del diseñador en una sociedad cada vez más democrática. Luisa Martínez (1990) apunta que durante esta década "surgió un nuevo estilo de diseño en Suiza llamado 'diseño suizo’ o bien, estilo tipográfico internacional” (p. 137). Un movimiento impulsado por diseñadores que buscaron sistematizar los procesos del diseño gráfico, tipográfico y editorial, sus postulados se encaminaron hacia el orden compositivo y la utilización de tipografías Sans Serif (sin patines) o también llamadas de palo seco.

Las características de este estilo (estilo tipográfico internacional) incluyen: la unidad visual lograda por la organización asimétrica de elementos sobre una retícula, el uso de tipos sin patines (sobre todo la Helvética), tipografía justificada a la izquierda y rasgada a la derecha y fotografía objetiva. Lo más importante de este movimiento es la actitud que los diseñadores tomaron hacia su proposición, ya que definieron el diseño como una actividad importante de utilidad social. (Meggs, 1990, p. 379).

En las décadas de 1920 y 1930, se dio el antecedente en la implementación de sistemas de construcción geométrica en el diseño editorial. Hacia 1928, Jan Tschichold formuló las normas de la tipografía moderna mediante su libro La tipografía moderna, con el que se propuso sistemas de ordenación compositiva en la comunicación visual y el diseño gráfico objetivo-funcional (Brockmann, 1982). Esta transformación del diseño gráfico llevó a una 
forma de trabajo mucho más riguroso de lo convencional, donde los elementos de la composición estuvieron debidamente justificados, fue una etapa en el que las escuelas de diseño y la práctica profesional caminaron en la línea del orden, sistematización y claridad, elementos que dieron inicio al nacimiento de la 'retícula' como elemento geométrico organizacional para los diferentes soportes del diseño gráfico, pero sin una declaración formal. Fue hasta 1961 cuando surgió por primera vez una breve exposición literaria y gráfica de la retícula en el libro Problemas de configuración del diseñador gráfico del autor Niggli Verlag. En el escrito de Verlag, no se detalla el uso o manejo de la retícula, solo se entendió e imitó con base en ejemplos aplicados en revistas y anuncios publicitarios. Debido a la inexistencia de un manual de uso, en 1982 surgió el libro 'Sistema de retículas' de Josef Müller Brockmann (1982), recurso que puso los medios estratégicos para resolver problemas de comunicación visual, explicando a la comunidad de diseñadores paso a paso la función y empleo reticular; un soporte geométrico que permitió organizar elementos gráficos, tipográficos, fotográficos, etcétera. Desde la década de 1950 la publicidad de impresos despuntó en forma significativa, debido a que los países con más desarrollo fortalecieron su economía producto de la política capitalista. Martínez (1990) señala que "en Estados Unidos, la comercialización dio lugar a una nueva sociedad de consumo y como resultado la publicidad entró a su época de oro, por el principal medio de comunicación: las revistas" (p. 140). Con la retícula establecida como un soporte geométrico estratégico, el diseño editorial potencializó su perspectiva de innovación marcando una tendencia de trabajo normativo y profesional.

La siguiente imagen ilustra la construcción de una retícula con base en 20 campos cuadrados, -caso ficticio- estrategia establecida como correcta, de acuerdo a las necesidades de la publicación. Se observa cuatro columnas y cinco líneas horizontales de campos cuadrados para posicionar textos e imágenes, tal cantidad de campos se determinó con el fin de ofrece mayor posibilidades de soluciones. Cuanto más divisiones tenga una retícula, mayor posibilidad dinámica y viceversa. Se puede diseñar cualquier cantidad de páginas en una publicación como es el caso de estas páginas de revista, y mantener un sistema de composición integral. En la actualidad, el uso de la retícula se emplea tanto en proyectos editoriales análogos como en publicaciones digitales de clase profesional.
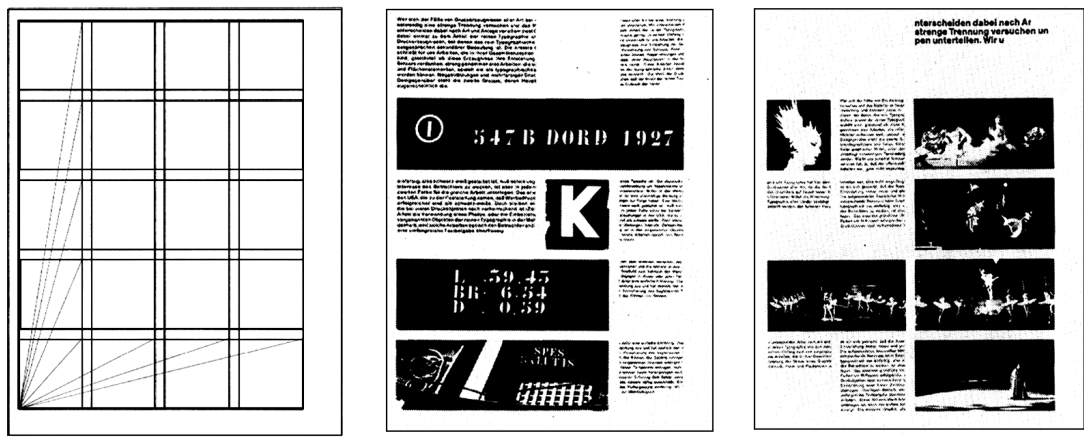

Figura 4. La retícula como sistema de orden visual. Fuente: Müller Brockmann, 1992, p. 81 
Tanto en la industria editorial como en la publicitaria se observa una incontable cantidad de material impreso -de todo tipo-, oportunidad de desarrollo para los diseñadores gráficos. Las escuelas y facultades donde se imparte la carrera de diseño gráfico y diseño y comunicación visual, incluyen en su programa curricular la enseñanza de los fundamentos del diseño, la normatividad tipográfica, leyes de composición, la metodología del diseño, entre otras materias, es decir, una educación académica formal, sistematizada, en donde se inculcan principios y valores para la formación profesional. Tal parece que lo aprendido en la universidad es una cosa y la práctica profesional otra. Existe una especie de puente inconcluso que no termina de enlazar a la academia con la práctica profesional. Cada profesional del diseño se consolida de forma única, como consecuencia de su contexto y experiencias, en donde las decisiones que se toman durante el proceso de maduración construyen un estilo propio, una ética que delimita lo correcto y lo no conducente. Cada diseñador tiene la libertad de decisión: si toma el camino de la normatividad o uno alterno que quebrante las normas establecidas. Al respecto, Ana Ma. Narro (2009) señala que:

El ser humano es libre: cada quien es responsable de sus propios actos y de su propia vida. Los que identifican la elección libre con el deseo, con el ardor de la sensibilidad, no están en lo correcto, pues la elección consciente no tiene nada en común con los seres que carecen de 'razón'. (p. 8).

Un ejemplo de camino alterno que desafía el academicismo se muestra a continuación: el bucket de CD diseñado por Nicky Lindeman y Chris Austopchuck omite todo tipo de norma, ley o principio del diseño editorial, no existen retícula, ni fuente tipográfica que indique una composición sistemática, sin embargo, es algo bien visto por el cliente Sony Music Entertainment Inc. Al respecto, Joshua Berger (1994) escribió “La retícula pura de la modernidad ha sido formalmente rechazada por el nihilismo de la cultura joven industrializada" (p. 11). Por tanto, no se puede establecer si un camino u otro es el correcto.
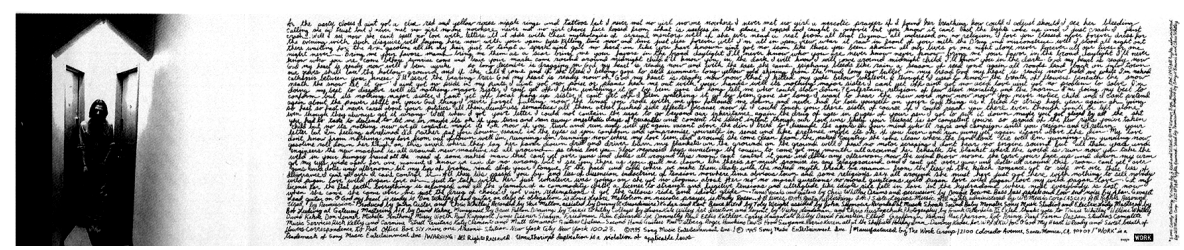

Figura 5. Diseño posmoderno en Bucket de CD. Fuente: Héller - Ilic, 2004. p. 77

El proyecto de la tipografía de estilo Sans Serif-tipo de letra sin patines o remates- se pronunció como uno de los exponentes de la modernidad, mientras que a los tipos romanos -clásicos- se relegaron a un segundo plano y se referenciaron al pasado. En Europa los movimientos artísticos encontraron una forma de expresión en la tipografía y el diseño 
gráfico, con lo que se creó un vocabulario casual (Martínez, 1990). Expresiones artísticas como el dadaísmo, constructivismo, De Stijl, entre otras más, fincaron el inicio de la experimentación tipográfica en donde se valoró la forma además de la función lingüística y con ello una nueva manera de hacer y comprender el diseño tipográfico. Uno de los responsables en el desarrollo de la tipografía fue el diseñador Jan Tschichold. A decir de Martínez (1990), Tschichold buscó un contenido espiritual y una belleza más relacionadas con los materiales a emplear y no únicamente con la racionalidad formal.

La confrontación de pensamientos modernidad y posmodernidad que se estableció a finales del siglo pasado, se puede ilustrar con la postura de la formas tipográficas; el tipo Helvética es la cara más representativa del periodo de la modernidad, -fuera de cualquier ornamento- significó la objetividad, racionalidad, claridad, legibilidad, y el estilo moderno, con un espíritu de democratización se convirtió en la fuente más utilizada en el mudo, desde su reconfiguración en 1957 por Max Miedinger, y hasta la actualidad. Para los conservadores del diseño y la tipografía, es una fuente tan bien diseñada que no cebe en ella corrección alguna, sin embargo, existen detractores posmodernos que opinan lo contrario: que es ubicua, carente de identidad e inexpresiva. A continuación se muestran dos fuentes tipográficas que ejemplifican ambos pensamientos antagónicos.
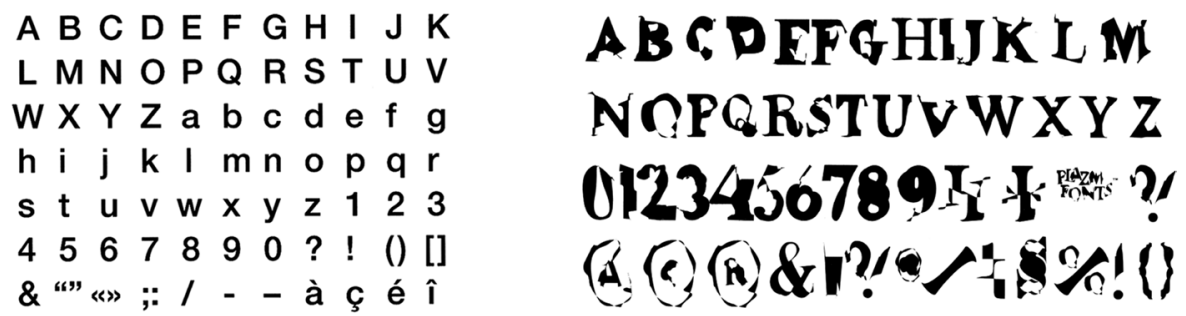

Figura 6. Tipografía moderna y posmoderna: Helvética y Erosive.

Fuente: Pohlen, 2011, p. 408 - Poinor, 2003, p. 64

La fuente tipográfica Erosive diseñada por Peter Mc.Cracken (parte superior derecha), despliega en su forma el espíritu antagónico del periodo posmoderno; figura que rechazó a las buenas costumbres y la normatividad académica. La década de 1990 estuvo permeada por el estilo controversial del grunge y el grafismo sucio del punk, estilos de diseño posmoderno que utilizaron las letras para deconstruir los textos, en los que se protagonizó más a la forma, que ha su función literaria. Por su parte Rick Poynor (2003) señala que "El grunge al igual que el punk, era enérgico, irrespetuoso, airado y su medio era la subcultura, aunque no permanecería allí por mucho tiempo" (p. 63). El hecho de que Mc.Cracken haya presentado un diseño de letras de estilo fragmentado, descompuesto, de formas ac- 
cidentadas y alejadas de la geometría, en el contexto de los 1990, significó la tendencia del diseño y la postura antagónica característica de aquella década.

Con la incursión de la computadora personal en los 1980, el diseño gráfico tuvo un desarrollo exponencial en las siguientes décadas. La computadora es una herramienta que cambió la forma del trabajo tradicional del diseño; de la práctica análoga, al sistema analógico. La técnica tradicional fue superada en un sinfín de posibilidades, los editores con los que cuentan los programas de diseño, fueron una invitación abierta a la experimentación tipográfica. La computadora no hace a los diseñadores ni mejores, ni más creativos, lo que si hace es el trabajo más rápido, tanto para la edición como para la producción de material gráfico. Como respuesta a la problemática en el uso de la tipografía, Rob Carter (1997) -estudioso del diseño- estableció 19 normas con el fin de ayudar a los diseñadores a poner orden en sus propuestas de diseño, advierte: en todos los casos, la recomendación es conocer las normas antes de romperlas.

Norma 1. Para una legibilidad óptima, elija fuentes clásicas y habituales ya probadas.

Norma 2. Procure no utilizar demasiadas fuentes diferentes a la vez.

Norma 3. Evite combinar fuentes que se parezcan demasiado.

Norma 4. Un texto en mayúsculas entorpece la lectura. Utilice letras en caja alta y baja para optimizar la legibilidad.

Norma 5. Para los bloques de texto, utilice aquellos cuerpos que, según se ha demostrado, facilitan la lectura.

Norma 6. Evite emplear demasiados cuerpos y grosores diferentes a la vez.

Norma 7. Use tipos para texto del grosor adecuado. Evite fuentes demasiado gruesas o demasiado finas.

Norma 8. Utilice fuentes de anchura media. Evite las fuentes demasiado anchas o demasiado estrechas.

Norma 9. En los bloques de texto, utilice un interletrado y un espacio entre palabras coherente, para dar solución de continuidad.

Norma 10. Utilice líneas de la longitud adecuada. Las líneas demasiado cortas o demasiado largas interrumpen la lectura.

Norma 11. En el texto seguido, utilice el interlineado que lleva al ojo con facilidad de una línea a la siguiente.

Norma 12. La mejor legibilidad se consigue con una alineación izquierda en bandera a la derecha.

Norma 13. Procure obtener finales de línea coherentes y rítmicos.

Norma 14. Indique los párrafos con claridad, pero procure no alterar la integridad y la coherencia visual del texto.

Norma 15. Evite viudas y huérfanas siempre que pueda.

Norma 16. Destaque discretamente elementos del texto sin alterar la fluidez de la lectura.

Norma 17. Mantenga siempre la integridad del tipo. Evite cambiar el set de forma arbitraria. 
Norma 18. Alinee las letras y las palabras sobre la línea base.

Norma 19. Cuando trabaje con el tipo y el color, asegúrese de que existe suficiente contraste entre tipo y fondo (Carter, 1997, p. 10-21).

En la década de 1960, se dieron expresiones de experimentación como una necesidad de liberación, una especie de consenso mundial repudió los moldes 'racionales' del periodo de la modernidad; los sucesos de dos guerras mundiales, las vejaciones del holocausto, la bomba atómica y la guerra de Vietnam, fueron los detonantes principales. Se cuestionó sobre si lo hecho en medio siglo fue lo correcto, si la ética empleada tuvo los argumentos para justificar lo realizado. Al margen de una enorme lista de notables inventos y significativos avances en la ciencia y la tecnología, al final de este periodo de la modernidad el resultado arroja un saldo negativo. En las siguientes décadas, el problema político, social y filosófico mundial tuvo reacciones en el arte y el diseño; con el antecedente de las vanguardias artísticas como movimientos serios que rompieron los esquemas del arte tradicional, para la segunda mitad del siglo XX, surgen diseñadores y artistas posmodernos que también rompieron paradigmas, cuestionaron el modelo académico, rechazaron la normatividad y el orden sistemático. Artistas referentes de la posmodernidad son David Carson, Stefan Sagmeister, Neville Brody, Jeffery Keedy, Rob Carter, entre otros. Con base en la expresión visual, sus trabajos muestran un metalenguaje que va más allá del significado literario. El significado de posmoderno indica al periodo que sucedió después de la modernidad, no obstante, la definición es incierta, porque carece de fundamentos sólidos, es un eclecticismo que se queda en ideas subjetivas, a pesar del reconocido potencial expresivo, el protagonismo de los elementos compositivos y los múltiples artistas expositores, fue duramente criticado por la academia. En un acercamiento a su definición Wellmer (1985) explica que:

El concepto de postmodernidad o postmodernismo se ha convertido en uno de los conceptos más esquivos en la discusión estética, literaria y sociológica de la última década. El término postmodernidad pertenece a una red de conceptos y pensamiento "post" -sociedad postindustrial, postestructuralismo, postempirismo, posttracionalismo-, en los que, según parece, trata de articularse a sí misma la conciencia de un cambio de época, conciencia cuyos contornos son aun imprecisos, confusos y ambivalentes, pero cuya experiencia central, la de la muerte de la razón, parece anunciar el fin de un proyecto histórico: el proyecto de la modernidad, el proyecto de la Ilustración europea, o finalmente también el proyecto de la civilización griega y Occidental. (p. 44).

Las expresiones logradas por los artistas y diseñadores de la época en el corto periodo del diseño gráfico posmoderno (1980 - 2005), permitió observar una ruptura -casi total-con los fundamentos del diseño y las normas tipográficas. Se entiende el rompimiento de normas como una estrategia del proceso creativo, no como respuesta antagónica o producto del nihilismo. La experimentación y el quebrantamiento de normas se concibe como un trabajo sistematizado, controlado en el espacio de laboratorio académico o bien, en el ám- 
bito profesional. A continuación se presentan los trabajos de Warren Lehrer y Frank Edie cuyas características formales del diseño posmoderno son: aparente rompimiento con los principios y normas del diseño y la tipografía, ilegibilidad, falta de organización sistemática, ausencia de la retícula, variedad excesiva de fuentes y estilos de letra, disparidad de cuerpos tipográficos, plecas, barras y líneas con sentido ornamental, sobre posición de elementos que se atropellan entre sí.
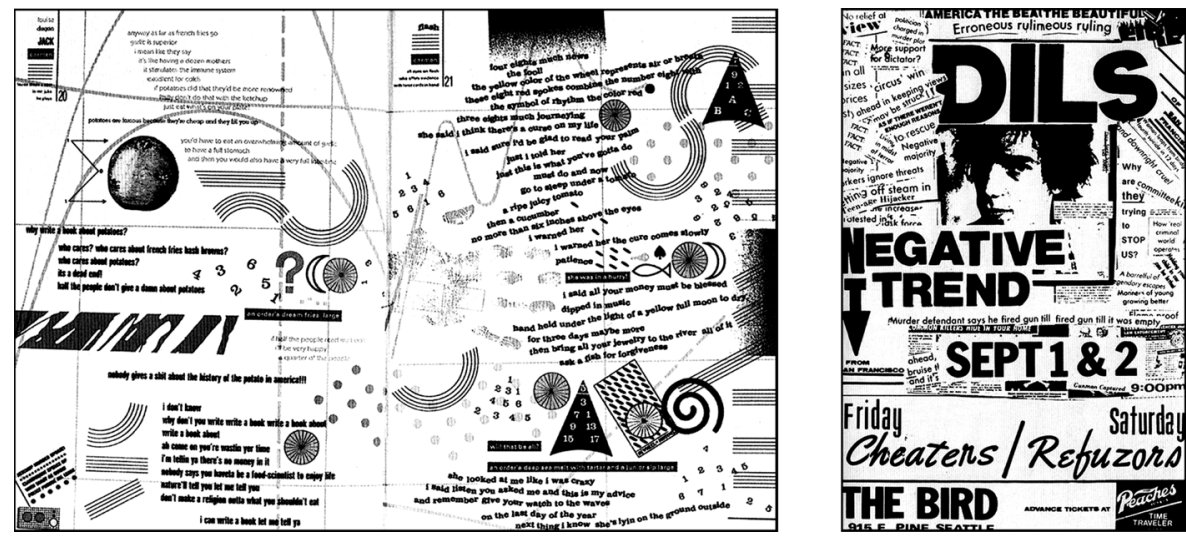

Figura 7. Diseño editorial posmoderno de la década de 1980. Fuente: Poinor, 2003, p. 41-131

\section{Conclusiones}

Las posturas polarizadas en el diseño es un fenómeno a nivel mundial; si bien, es cierto que las disciplinas del diseño profesional se rigen con base en la normatividad, existe otra posición filosófica que desafía la estructura y la sistematización. Las normas tipográficas y los principios del diseño fueron pilares en la construcción de la profesión del diseño gráfico, por lo que se concibe ser respetadas, solo se contempla su quebrantamiento como estrategia del proceso creativo. Aun cuando la modernidad postula a la razón como principal eje de acción, la comunicación visual es valorada como un sistema de trabajo alterno, humanista, capaz de expresar sentimientos personales y en el que se desenfoca a la metodología científica y la objetividad de las estructuras. En la actualidad existen ortodoxos del diseño que desaprueban las expresiones posmodernas de los liberales, mientras que éstos últimos, rechazan enérgicamente los postulados de las instituciones académicas. Entonces, frente a estas dos formas de pensamiento, la disyuntiva establece que el camino a seguir dependerá de la conciencia de cada individuo, la decisión sobre lo éticamente 
correcto o incorrecto en la práctica del diseño es un asunto que compete a los valores de la moral personal. La cuestión de quien es el diseñador, y cual es su función en la sociedad; es posible encontrar las respuestas en el campo de la ética, donde se construyen las acciones y la intrínseca relación con la capacidad de reflexión crítica. (García G., 2012). Cada diseñador se construye en formación singular, de causas multifactoriales, en el que día a día forja su carácter, define un estilo propio, fortalece el sentido de identidad y pertenencia. Tanto en el práctica profesional del diseño, como en la vida, la ética en todo momento pretende ser congruente con lo que se piensa y se dice, y lo que se dice y se hace.

\section{Lista de referencias bibliográficas}

Bauman, Zygmunt. (2005) ética posmoderna. Reino Unido: Siglo XXI Editores.

Berger, Joshua. (1994) En cuanto al diseño, tipografía y legibilidad. Estados Unidos: Plazm. Brüning, U. (1988) La publicidad en su lugar: de la tipografía a la publicidad. Alemania: Experiment Bauhaus.

Carter, Rob. (1997) Diseñando con tipografía 4, tipografía experimental. España: RotoVision. Droste, Magdalena. (1991) Bauhaus. Alemania: Benedikt Taschen.

Elam, Kimberly. (2014) La geometría del diseño. España: Gustavo Gili.

García G., Dora Elvira. (2012) Ética, persona y sociedad. México: Porrúa.

Gebhard, Ernst. (1979). Trabajo en el taller de publicidad. Alemania: Proposición de la forma. Habermas, Jürgem. (1981) Modernidad versus posmodernidad. España: Critique.

Martínez Leal, Luisa. (1990) Treinta siglos de tipos y letras. México: Tilde / Universidad Autónoma Metropolitana.

Meggs, Philip, B. (1984) Historia del diseño gráfico. Estados Unidos: Alphabet Press.

Müller-Brockmann, Josef. (1992) Sistemas de retículas. España: Gustavo Gili.

Narro García, Ana María. (2009) Principios de ética. México: Porrúa.

Poynor, Rick. (2003) No más normas, diseño gráfico posmoderno. España: Gustavo Gili.

Ruder, Emil. (1992) Manual de diseño tipográfico. España: Gustavo Gili.

Sparke, Penny. (2010) Diseño y cultura una introducción. España: Gustavo Gili.

Vilchis, Luz del Carmen. (2010) Historia del diseño gráfico en México 1910-2010. México: Instituto Nacional de Bellas Artes.

Wellmer, Albrecht. (2005) Sobre la dialéctica de la modernidad y posmodernidad. España: Antonio Machado.

\section{Lista de referencias de imágenes}

Elam, Kimberly. (2014) La geometría del diseño. España: Gustavo Gili. Heller, Steven - Ilic, Mirko. (2004) Escrito a mano. España: Gustavo Gili. Müller-Brockmann, Josef. (1992) Sistemas de retículas. España: Gustavo Gili. 
Pohlen, Joep. (2011) Fuente de letras [sobre tipos de lera]. España: Taschen.

Poynor, Rick. (2003) No más normas, diseño gráfico posmoderno. España: Gustavo Gili. Wyman, Lance. (2014) Lance Wyman. México: Museo Universitario de Arte Contemporáneo - UNAM.

\begin{abstract}
In the framework of Graphic Design, the documented expressions of the different periods are part of the history of man, and although the first graphic and writing traces did not follow a normative pattern, the creations were given in a slow process -with adversities-, but finally effective for the evolution. Inevitable confrontations of thought revolutionized each epoch, signifying small and great achievements for humanity. Graphic design and typography are not left out of the transformations. The foundations of design, typographic standards and methodology were factors that systematized the processes.

This paper deals with graphic design and typography with a visual communication perspective, the crossover with ethics in professional performance, from the pragmatic, semantic and syntactic implications of some design cases that presented, the analysis and confrontation with what could be right or wrong in the meaning of a design. The starting point for this crossing is based on the fundamentals of design and typographic norms, structures proposed as regulatory systems or order, in confrontation with the staging of non-conventional graphic supports, where the academic principles of design are violated and typographic norms are broken. At the end of the document, a reflection will be made on the current manifestations of graphic design and the ethical position of designers, both conservative and liberal; if a present "anything goes" aspects that can be analyzed and from which conclusions can be drawn from the above.
\end{abstract}

Keywords: ethics - reason - standards - design - typography.

Resumo: No marco do Desenho Gráfico as expressões documentadas dos diferentes períodos, são parte da história do homem, e apesar que os primeiros vestigios gráficos e de escritura não seguirão um padrão normativo, as criações se deram de um processo lento -com adversidades-, porém finalmente efetivo para a evolução. O desenho gráfico e a tipografia nao ficam de lado nas transformaçõese. Essa escrita aborda o desenho gráfico e a tipografia com perspectiva da comunicacao visual, o cruzamento com a ética no desempenho profissional, apartir das implicações pragmáticas, semânticas e sintáticas de alguns casos de desenho que se apresentam, a análises e confrontação com lo que pudesse ser correto ou incorreto no significado de um desenho. Para tal cruzamento, o ponto de partida se sustenta nos fundamentos do desenho e nas normas tipográficas, estruturas planejadas como sistemas reguladores da ordem, na confrontação com a colocação em cena de suportes gráficos não convencionais, onde ficam vulneráveis os principios acadêmicos do desenho e se quebram as normas tipográficas. No final do documento faremos uma reflexao sobre as manifestações atuais do desenho gráfico e a postura ética do desenhador, tanto de conservadores como de 
liberáis; se na atualidade realmente "vale tudo", aspectos que poderão analizar-se e dos que se poderão tirar conclusões apartir do exposto.

Resumo: ética - razão - normas - desenho - tipografia.

[Las traducciones de los abstracts fueron supervisadas por el autor de cada artículo] 